узкоспециализированным изданиям, создаваемым и доступнымтолько им самим, так как подобные учебные пособия обычно не поступают в продажу, не выставляются на книжных ярмарках, а так и остаются достоянием одного ВУЗа, а то и одной кафедры.

Учитывая вышесказанное, следуетотметить, что преподавание нового иностранного языка «с нуля» (в нашем случае французского) студентам неязыковых ВУЗовпроходит иначе, чемобучениепервому «школьному» английскому. Оно коммуникативно, практически и профессионально ориентировано, проходит с опорой на русский и английский языки, его темпы гораздо выше. Методика проведения занятий по второму иностранному языку существенно отличается от методики обучения первому, что очень важно принимать во внимание в процессе лингвистической подготовки студентов неязыкового ВУЗа. Это позволяет выполнить со студентами ФГОС по специальности «Иностранный язык», используя несколько более упрощённую рабочую программу. И если не относиться к проблеме преподавания нового иностранного языка серьезно, если не мотивировать студентов современными формами и методами преподавания, более значительными окажутся доводы тех, кто полагает, что изучать новый язык в неязыковом вузе «с нуля» это напрасный труд, так как английский язык точно пригодится выпускнику в профессиональной деятельности, а другой -не обязательно.

В последнее время большая часть студентов всех профилей, в том числе технических,осознают важность лингвистической подготовки. Они понимают, что в настоящее время нет такого рода деятельности, в которой знание иностранных языков оказалось бы лишним. Большинство молодых людей стремятся стать не только хорошими профессионалами, но и всесторонне развитыми, высокообразованными личностями.Изучение и владение новыми иностранными языками обязательно внесет свой вклад в осуществление этого стремления.

$$
* * *
$$

1. Федеральный закон от 29.12.2012 N 273-Ф3 (ред. от 29.07.2017) «Об образовании в Российской Федерации».Статья 34, п. 4. URL: http://www.consultant.ru/document/cons_doc_LAW_140174/

2. Киреева 3. Р., Галимова Х. Х.Особенности обучения французскому языку как второму иностранному на языковом факультете //Филологические науки. Вопросы теории и практики: электрон.многопредм. науч. журн.Тамбов: Грамота, 2015. № 5 (47). Ч. I. С. 103 106.http://www.gramota.net/materials/2/2015/5-1/23.html

3. Синицына Т.А. Преподавание иностранного языка для студентов неязыковых вузов.Развитие образования, педагогики и психологии в современном мире. // Сборник научных трудов по итогам международной научно-практической конференции. Воронеж, 2016. № 3. С. 151.

4. Тенитилов С.В., Флеров О.В. Влияние современных педагогических идеалов на обучение иностранным языкам // Вестник Российского нового университета.№ 1. М.,2010. С. 95-99.

5. Флеров О.В. Особенности преподавания второго иностранного языка в нелингвистическом вузе // Современное образование. М., 2015.№ 1. С.1-25.

\title{
Потёмкина Е.B. \\ История развития концепции «Словаря языка Достоевского»: от символа к тезаурусу
}

Московский государственный университет имени М.В. Ломоносова (Россия, Москва)

doi: $10.18411 / s p c-26-12-2017-04$

idsp: 000001:spc-26-12-2017-04

\section{Аннотация}

Статья посвящена некоторым базовым положениям концепции «Словаря языка Достоевского», а также истории их разработки.Рассмотрена ключевая единица в структуре словаря, обозначаемая термином «идиоглосса».Описана предложенная Ю.Н. Карауловым и И.В. Ружицкимметодика построения авторского тезауруса на основе выделения символической парадигмы идиоглоссы. На основе анализа 
контекстного употребления слова «пожар» предложен фрагмент реконструированного тезауруса Достоевского.

Ключевые слова: Словаря языка Достоевского; языковая личность; тезаурус; символ; идиоглосса; пожар.

Словарь языка Достоевского (далее - СЯД) по своим базовым характеристикам представляет собой словарь тезаурусного типа, так как предметом описания в нём являются лексические единицы, которые несут концептуальное содержание, а точнее, лексические единицы, характеризующие особенности индивидуального стиля (идиолекта) Достоевского. Изначально СЯД предполагался как лексикографическая серия, которая должна была включать несколько типов словарей: базовый, частотный, топонимов, грамматических слов, фразеологизмов и др., - и первым в этом ряду стал словарь «Лексический строй идиолекта». Его словник составили лексические единицы, структурирующие мир языковой личности автора, которые обозначаются термином «идиоглосса». Словарная статья в этом словаре ориентирована на раскрытие мира Достоевского и содержит описание ключевых параметров организации языковой личности. Она включает в себя описание каждого из значений лексикографируемой единицы, описание её в составе собственных имён, фразеологических единиц, пословиц и поговорок. При этом наиболее важным является то, в чём заключается авторская вариация общеязыковых норм. В частности, значения в словарной статье упорядочены так, чтобы отражать функциональную значимость смыслов, от наиболее значимых, к наименее значимым.Всё в словаре подчинено тому, чтобы словник стал «сокровищницей мыслей и художественных образов Достоевского» [СЯД 2001:XVI]. Каждая словарная статья, включённая в идиоглоссарий Достоевского, должна, согласно концепции авторов, нести в себе мощный идеологический заряд.

С точки зрения динамики развития концепции СЯД надоотметить, что «Лексический строй идиолекта» имеет три выпуска. Первый выпуск включает 114 слов из всего алфавита (Ангел - Усмешка), в двух последующих алфавит распределён: второй выпуск содержит слова на буквы А-Л, третий выпуск - М-Я. При этом второй и третий выпуски содержат как идиоглоссы, так и не идиоглоссы, что подчёркивает особенность функционирования первых единиц. Авторы словаря подчёркивают, что при анализе идиолекта писателя нет смысла включать в словник «подряд все лексические единицы, встретившиеся в текстах писателя, поскольку одной из основных функций языкового мышления, определяющей процесс познания в целом, является редуцирование, сведение путём генерализации всего разнообразия слов и смыслов к единому концептуальному ядру» [Караулов, Ружицкий2015: 16]. Задачей составителей авторского тезауруса,таким образом, является выявить это ядро, так чтобы оно имело порождающий потенциал.

Итак, в отличие от общеязыковых тезаурусов, целью которых является систематизация максимально полной лексической базы в соответствии с семантической природой входящих в неё единиц, словник СЯД включает в себя ограниченный набор единиц, идиоглосс, которые в совокупности составляют идиоглоссарий Достоевского. По определению Ю.Н. Караулова, идиоглоссы - это концептуальные образования, из которых складывается картина мира и которые, соответственно, вбирают в себя специфику авторского стиля. С точки зрения субъективного авторского мировидения они представляют собой «тезаурусо-образующие понятия». По отношению к тексту они выполняют роль ключевых слов, позволяющих воспроизводить в свёрнутом виде содержание конкретного текста; по отношению к авторскому идиолекту - выступают в роли «единиц индивидуального авторского лексикона». Основным критерием выделения слова в качестве идиоглоссы является то, что оно образует в пространстве 
текста «точки концентрации смысла, вокруг которых формируются специфические ассоциативные поля» [СЯД 2001:XXXVI].

Как было сказано выше, «Лексический строй идиолекта»должен был стать одним из этапов создания дифференциально-распределительного словаря-серии, однако динамика развития концепции СЯД такова, что авторам пришлось отказаться от первоначального плана. Характер словоупотребления Достоевского потребовал более глубокой проработки структуры и содержания словарной статьи, которая в новой версии должна охватывать большее количество параметров. Для верификации идиоглоссного статуса слова была разработана специальная методика, состоящая из шести шагов(см. [Ружицкий 2015: 48]). Обязательным в составе словарной статьи стал Комментарий, включающий в себя зоны, соответствующие трём уровням организации языковой личности: вербально-семантический (морфологические особенности слова, сочетаемость, словообразовательное гнездо и др.), когнитивный (использование в составе афоризмов, в отсылке к прецедентным текстам, тропы, употребление в символическом контексте и др.) и прагматический (иронический контекст, примеры языковой игры и др). Основываясь на новых теоретических положениях, авторы начали издаватьмноготомный «Идиоглоссарий» Достоевского. К настоящему времени изданы следующие тома: том первый «А-В» $(2008$ г.), том второй «Г-3» $(2010$ г.), том третий «И-М» (2012 г.), том четвёртый «Н-По» (2017 г.). И как логическое продолжение концепции авторского тезауруса, параллельно с процессом составления «Идиоглоссария» авторами СЯД разрабатываются пути составления синоптической части, т.е. той части, которая бы отражала систему взаимосвязи идиоглосс. Разработка данной составляющей любого словаря тезаурусного типа всегда является наиболее сложным этапом, так как требует глубокого осмысления всего объёма представленного в словаре лексического материала с целью представить языковую личность автора в целостности. Стоит подчеркнуть, что такая попытка по отношению к авторскому тезаурусу, а тем более к тезаурусу Достоевского предпринимается впервые.

Исходя из логики концепции СЯД, можно предположить, что в основе систематизации тезауруса должно лежать то, что вмещает в себя базовые для Достоевского смыслы, то, что определило весь творческий путь писателя, от первого до последнего созданного им текста. При этом целесообразно обратиться к высказываниям самого Достоевского, который уже в 1839 г. писал в письме к брату: «Человек есть тайна. Её надо разгадать, и ежели будешь её разгадывать всю жизнь, то не говори, что потерял время; я занимаюсь этой тайной, ибо хочу быть человеком». Обращаясь же к анализу словоупотребления слова человек в текстах Достоевского, нельзя не заметить, какую роль в них автор отводил размышлениям над этой тайной. Другими словами, идиоглоссарий Достоевского отвечает принципу «конусообразности» любого тезауруса, о которой писал Ю.Н. Караулов, имея в виду, что вершиной, наиболее подробно разработанной (в семантическом отношении) и, соответственно, отправной точкой в лексической базе языка, всегда является именно ЧЕЛОВЕК. Что касается дальнейшего развития ядерной структуры словаря Достоевского, то она определяется, согласно идее авторов СЯД, не как в общеязыковом тезаурусе естественными семантическими связями, существующими в языке (на основе которых в идеографии выделяются семантические сферы, которые дальше делятся на семантические классы, и далее - группы), а особенностями художественного осмысления писателем жизни ЧЕЛОВЕКА.

«Итак, Достоевский определяет человека как тайну, загадку, которую надо разгадать, и которая оказывается зашифрована в его текстах. В качестве инструмента для шифрования смысла как ничто другое подходит символ. 
Интерес Достоевского кразличного рода символам неоднократно подчёркивался исследователями <...>. Объясняется это самыми разными причинами, наиболее очевидной из которых представляется стремление автора отразить мир во всех его противоположностях, противопоставить образ, задаваемый символом, логическому сознанию» (что исходит и изэтимологи слова «символ», ср. греч. sýmballo - 'соединяю, сталкиваю, сравниваю'). Важнейшим свойством символа является возможность слов с конкретной семантикой в определённом контексте выражать абстрактные значения, именно поэтому у Достоевского символ - это очень часто выход на идею всего произведения. Воспринимая символическую природу текста Достоевского, читатель, переживая «эффект узнавания», устанавливает контакт с автором и испытывает чувство удовлетворения от прочитанного[Ружицкий 2015: 56].

Отталкиваясь от устоявшегося восприятия текстов Достоевского как текстовзагадок, а также принимая во внимание, что именно эффект узнавания символов обеспечивает связь автор-читатель, составители СЯД сделали предположение, что в основу выделения ядерных элементов словаря могут быть положены символические значения. Как отмечает Ю.Н. Караулов, всего лексических единиц, выполняющих у Достоевского функцию символизации, порядка шестидесяти. Среди них авторы СЯД в результате анализа лексикографических данных, полученных при создании «Лексического строя идиолекта» и первых четырёх томов «Идиоглоссария», выделяют помимо символического ядра ЧЕЛОВЕК ещё шестьидиоглосс-символов, которые могут составлять у Достоевского амбивалентные пары: ЖИЗНЬ, СТРАХ, ЛЮБОВЬ, БОЛЕЗНЬ, СМЕРТЬ, СМЕХ(подробнее см. [Ружицкий 2015]).

С точки зрения методологии составления тезауруса символы являются удобными единицами классификации, т.к. часто складываются в группы, символические парадигмы, которые являются следующим лексикографическим шагом при построении синоптической части словаря, и которые в значительной степени будут отличаться от группировки слов в общеязыковых тезаурусах русского языка. Так, например, по замечанию И.В. Ружицкого, знаковой для языковой мира Достоевского будет группа слов-символов со значением 'орудие убийства':ТОПОР, НОЖ, РЕВОЛЬВЕР, ПЕТЛЯ (ШЁЛКОВЫЙ СНУРОК, ГВОЗДЬ), БРИТВА (ОБМОТАННАЯ ШЁЛКОМ), ПЕСТИК, ПРЕСС-ПАПЬЕ, ПИСТОЛЕТ. «МеждУ авТорским вЫбором орудия убийства и персонажем, его совершившим, существует определённая и значимая связь, которая и становится своеобразным дифференциальным признаком значений соответствующих слов-символов»[Ружицкий 2015: 65]. Соответственно, исходя из этой ономасиологической «связи» слова могут входить в разные концептуальные сферы и «притягивать» к себе разные идиоглоссы.

Такие слова, выступающие в роли символов в текстах Достоевского, как пожар, пламя, огоньбудут, скорее всего,исходя из лексикографического анализа, входить в разные группы и, соответственно, концептуальные сферы, тогда как, например, в семантическом словаре Н.Ю. Шведовой они входят в единую группу «Огонь» (общая группа слов: костёр, огнище, огонь, пал, пламя, пожар, польмя, пыл, факел), которая включена на следующей ветви иерархии в семантический класс слов «Космос. Земля. Природные образования» (см. [Шведова 2002]).

Подробный экспериментальный фрагмент тезауруса(рассмотрены «символические» поЛЯ НАСЕКОМОЕ, ПРЕСТУПЛЕНИЕ, КАМЕНЬ, ГРАНИЦА и др.), а также синоптическая часть, построенная на основе описанного, символьного, подхода представлены в [Ружицкий2015].В рамках данной работы в качестве примера соотнесения отдельно взятого слова, выделенного в СЯД в качестве идиоглоссы, с общей структурой тезауруса, возьмём слово ПОЖАР, на символическое значение 
которого неоднократно указывалось исследователями творчества Достоевского [Топоров 1995; Чернова 1996]. В общем виде, пожар имеет в творчестве Достоевского два основных символических значения: общеязыковая символизация пожара как уничтожения (антитезы жизни) и присущая именно текстам Достоевского символизация пожара как очищения. Первое из названных символических значений актуализируется в наиболее явном виде в романе «Бесы», а второе значение -в рассказе «Господин Прохарчин», а также в Эпилоге «Преступления и наказания» (см. [Чернова 1996]).

Представим некоторые из контекстов, на основе которых можно реконструировать фрагмент тезауруса Достоевского (нумерация страниц здесь и далее даётся по[Достоевский 1972-1990]).

Повечеру пришел первый писарь Судьбин и объявил, что след отыскался, что видел он беглеца на Толкучем и по другим местам, ходил за ним, близко стоял, но говорить не посмел, а был неподалеку от него и на пожаре, когда загорелся дом в Кривом переулке(Господин Прохарчин 246).

По временам Ордынов думал, что всё это еще сон, даже был в этом уверен; но кровь ему бросилась в голову, и жилы напряженно, с болью, бились на висках его. Он выпустил гвоздь, встал с постели и, качаясь, пробираясь, как лунатик, сам не понимая своего побуждения, вспыхнувшего целым пожаром в крови его, подошел к хозяйским дверям и с силой толкнулся в них; ржавая задвижка отлетела разом, и он вдруг с шумом и треском очутился среди хозяйской спальни (Хозяйка 281) Завод, вверенный, кажется, управлению близкого и любимого родственника, тоже подвергся несчастной участи и сгорел, причем в пламени пожара погиб и сам его родственник. Согласитесь, потеря ужасная! Тогда Мурин, рассказывают, впал в плачевное уныние; стали опасаться за его рассудок (Хозяйка 286). Всё пламя, весь пожар, пламеневший в груди его, словно истлели и угасли в один миг и на один миг; он с смущением опустил глаза и боялся смотреть на нее (Хозяйка 303 ).

Мелькнула перед ним и фигура того старика с геморроидальным лицом, в ветхом, чем-то подпоясанном ватном халатишке, отлучившегося было еще до пожара в лавочку за сухарями и табаком своему жильцу и пробивавшегося теперь, с молочником и с четверкой в руках, сквозь толпу, до дома, где горели у него жена, дочка и тридцать с полтиною денег в углу под периной (Господин Прохарчин 250).Господин Прохарчин бежал, бежал, задыхался... рядом с ним бежало тоже чрезвычайно много людей, и все они побрякивали своими возмездиями в задних карманах своих кургузых фрачишек; наконец весь народ побежал, загремели пожарные трубы, и целые волны народа вынесли его почти на плечах на тот самый пожар, на котором он присутствовал в последний раз вместе с попрошайкой-пьянчужкой. (Господин Прохарчин 250)Тут уж нечего было останавливаться: Марк Иванович не вытерпел и, видя, что человек просто дал себе слово упорствовать, оскорбясь и рассердившись совсем, объявил напрямки и уже без сладких околичностей, что пора вставать, что лежать на двух боках нечего, что кричать днем и ночью о пожарах, золовках, пьянчужках, замках, сундуках и черт знает об чем еще - глупо, неприлично и оскорбительно для человека(Господин Прохарчин 251). Дети и пятаки, пятаки и дети вертелись на ее языке в непонятной, глубокой бессмыслице, от которой все отступились после тщетных усилий понять; но баба не унималась, всё кричала, выла, размахивала руками, не обращая, казалось, никакого внимания ни на пожар, на который занесло ее народом с улицы, ни на весь людлюдской, около нее бывший, ни на чужое несчастие, ни даже на головешки и искры, которые уже начали было пудрить весь около стоявший народ(Господин Прохарчин 252). 
Не могу сказать; но меня интересует при этом другое обстоятельство, так сказать, целый вопрос. Не говорю уже о том, что преступления в низшем классе, в последние лет пять, увеличились; не говорю о повсеместных и беспрерывных грабежах и пожарах; страннее всего то для меня, что преступления и в высших классах таким же образом увеличиваются и, так сказать, параллельно(Преступление и наказание 111).Много про пожары пишут...| Нет, я не про пожары. | Тут он загадочно посмотрел на Заметова; насмешливая улыбка опять искривила его губы. | Нет, я не про пожары, продолжал он, подмигивая Заметову. | А сознайтесь, милый юноша, что вам ужасно хочется знать, про что я читал(Преступление и наказание 125).Сама бывшая хозяйка его, мать умершей невесты Раскольникова, вдова Зарницына, засвидетельствовала тоже, что, когда они еще жили в другом доме, у Пяти углов, Раскольников во время пожара, ночью, вытащил из одной квартиры, уже загоревшейся, двух маленьких детей, и был при этом обожжен(Преступление и наказание 412).

В публичных каретах, в лавках, поймав хоть какого-нибудь слушателя, наводила разговор на своего сына, на его статью, как он помогал студенту, был обожжен на пожаре и прочее. Дунечка даже не знала, как удержать ее. Уж кроме опасности такого восторженного, болезненного настроения, одно уже то грозило бедой, что кто-нибудь мог припомнить фамилию Раскольникова по бывшему судебному делу и заговорить об этом. Пульхерия Александровна узнала даже адрес матери двух спасенных от пожара малюток и хотела непременно отправиться к ней(Преступление и наказание 414) Коегде люди сбегались в кучи, соглашались вместе на что-нибудь, клялись не расставаться, - но тотчас же начинали что-нибудь совершенно другое, чем сейчас же сами предполагали, начинали обвинять друг друга, дрались и резались. Начались пожары, начался голод. Все и всё погибало. Язва росла и подвигалась дальше и дальше (Преступление и наказание 420).

Конечно, всё может войти: курьезы, пожары, пожертвования, всякие добрые и дурные дела, всякие слова и речи, пожалуй, даже известия о разливах рек, пожалуй, даже и некоторые указы правительства, но изо всего выбирать только то, что рисует эпоху (Бесы 164). Всё лето свирепствовали по городам и селампожары, а в народе всё сильнее и сильнее укоренялся глупый ропот о поджогах. Грабительство возросло вдвое против прежних размеров (Бесы 267). Заречье пылало. Правда, пожар только еще начался, но пылало в трех совершенно разных местах, - это-то и испугало. I - Поджог! (Бесы 392) [Хроникер] Большой огонь по ночам всегда производит впечатление раздражающее и веселящее <... . Другое дело настоящий пожар: тут ужас и всё же как бы некоторое чувство личной опасности, при известном веселящем впечатлении ночного огня, производят в зрителе (разумеется, не в самом погоревшем обывателе) некоторое сотрясение мозга и как бы вызов к его собственным разрушительным инстинктам, которые, увы! таятся во всякой душе, даже в душе самого смиренного и семейного титулярного советника... (Бесы 394) [Шигалев П. Верховенскому] <...> каждая из действующих кучек, делая прозелитов и распространяясь боковыми отделениями в бесконечность, имеет в задаче систематическою обличительною пропагандой беспрерывно ронять значение местной власти, произвести в селениях недоумение, зародить цинизм и скандалы, полное безверие во что бы то ни было, жажду лучшего и, наконец, действуя пожарами, как средством народным по преимуществу, ввергнуть страну, в предписанный момент, если надо, даже в отчаяние. Ваши ли это слова <...>? (Бесы 418) [Хроникер] Оказалось, что он [Лямшин] знал довольно и довольно хорошо поставил на вид дело: трагедия с Шатовым и Кирилловым, пожар, смерть Лебядкиных и пр. поступили на план второстепенный. На 
первый план выступали Петр Степанович, тайное общество, организация, сеть. (Бесы 510).

В публицистике и письмах Достоевского (используется принятая в СЯД система сокращений):

Господин Скарятин («Русский листок», № 1) намекает даже на подметную литературу, на зарево пожаров и удивительно высоким слогом всё это расписывает. (pbc 61) Пожарный сезон! Разумеется, он наступил; не миновать же ему этот год. Между другими известиями, сообщаемыми в наши газеты, особенно характерно выдается известие в № 134 «Московских ведомостей» о пожаре в селе Измайлове, и не о пожаре собственно (пожар как пожар, везде бывают такие и много еще будет таких, по всей вероятности), но об особых обстоятельствах при этом пожаре. (pbd 142) Мистические идеи любят преследование, они им созидаются.Каждая такая преследуемая мысль подобна тому самому петролею, которым обливали полы и стены Тюльеризажигатели перед пожаром и который, в свое время, лишь усилит пожар и в охраняемом здании. (db 36) [Из описания рассуждений воображаемого прокурора] Вспомните, как хорошо ему [преступнику] послужил пожар в соседней улице в минуту совершения им преступления, потому что пожар, произведя тревогу, отвлек к себе внимание и дворников и всего околотка. (df 51)

[А.В. Корвин-Круковской] Одним словом, эта статья контракта совершенно походила на те статьи петербургских контрактов при найме квартир, где хозяин дома всегда требует, что если у жильца в его доме произойдетпожар, то должен этот жилец вознаградить все пожарные убытки и, если надо, выстроить дом заново. (ld 160) [H.Н. Страхову о приверженцах западноевропейского социализма] Они желают счастья человека и остаются при определениях слова «счастье» Руссо, то есть на фантазии, не оправданной даже опытом. Пожар Парижа есть чудовищность: «Не удалось, так погибай мир, ибо коммуна выше счастья мира и Франции». (le 214) [А.Г. Достоевской] Кстати, ты боишься пожаров, а вот теперь могут узнать (по слухам из почты), что прибыло к тебе много денег, смотри, Аня, ночует ли у вас Фома или кто-нибудь? Это серьезнеепожару. В газетах только и читаешь, что по всей России убийства и грабежи. (lg 100)

В силу своей символической природы ПОЖАР будет иметь амбивалентное значение, которое, с учётомпредставленной в СЯД словарной статьи ПОЖАР и учёта пересечения ассоциативных полей в СЯДидиоглосс, можно представить следующим образом.

\section{ЖиЗнь}

УНИЧТОЖЕНИЕ $\rightarrow$ БУНТ $\rightarrow$ БОЛЕЗНЬ/СМЕРТЬ $\rightarrow$ ОЧИЩЕНИЕ $\rightarrow$

I.1. Пожар

I.1.1. Идиоглоссы:

ад, адский, анархизм, бежать, бездна, бес, бесы, бред, бредить, бунт, бунтовать, деньги, дети, жизнь, зловещий, младенец, ненавидеть, огонь, опасность, переулок, пламя, погибнуть, революция, смерть, сон, тайна, убийство, умереть, человек.

I.1.3. Ассоциации: бежать, бояться, воспалённый, вспыхнуть, глаза, головёшка, грабёж, дети, дом, загореться, зажечь, зажигатели, зарево, здание, испугать, квартира, любить, любовь, малютка, мучение, несчастный, нигилизм, обожжен, обстоятельства, огненные глаза, огонь, петролей, погибать, погибнуть, поджог, подметная литература, отчаяние, полено, преступления, пылать, пьянство, развалины, сгореть, сезон, сердце, сжечь, сильный, смерть, спичка, тревога, убийство, убытки, угаснуть, участь. 
A реконструируемый фрагмент синоптической части СЯД, на основе предложенной И.В. Ружицкого, может быть представлен следующим образом:

(Б) ЖИЗНЬ $\leftrightarrow$ ВРЕМЯ<...>

Б.V. [начало - конец] заглохнуть, закончиться, начаться, покончить; окончательный, пожар, последний, прежний, твёрдый; полно, окончательно, твёрдо; начало, источник, конец, край, точка, черта

(В) ВРЕМЯ $\leftrightarrow$ СМЕРТЬ $<\ldots>$

B.II.1. умереть (умирать), погибать (погибнуть); кровавый, мёртвый, смертный; бытие, гроб, могила, погибель, пожар, смерть, сон

B.II.2. губить (погубить); война, гибель, дуэль, катастрофа

В заключение отметим, что предлагаемый авторами СЯД способ конструирования тезауруса Достоевского не является, безусловно, единственно возможным, однако основывается он на объективном многопараметровом лексикографическом анализе всего корпуса текстов писателя: с учётом ближних и дальних синтагматических связей, паратаксиса, ассоциативного окружения и когнитивного потенциала.

Публикачия подготовлена в рамках поддержанных РФФИ научных проектов (грант № 15-04-00135).

$* * *$

1. Достоевский Ф.М. Полное собрание сочинений: в 30 т. - Л.: Наука, 1972-1990.

2. Караулов Ю.Н., РужицкийИ.В. От словаря языка писателя к познанию его мира: о некоторых базовых концептах в творчестве Ф.М. Достоевского // Вопросы когнитивной лингвистики. -2015. - № 4 (045). - С. 16-22.

3. РужицкийИ.В. Язык Достоевского: идиоглоссарий, тезаурус, эйдос: Монография. - М.: ЛЕКСРУС, 2015. $-543 \mathrm{c}$.

4. Русский семантический словарь. Толковый словарь, систематизированный по классам слов и значений / РАН. Ин-т рус.яз. Под общ.ред. Н.Ю. Шведовой. Т. 3. - М.: Азбуковник, 2003. - 720 с.

5. СЯД 2008 - Словарь языка Достоевского: Идиоглоссарий (А-В) / Под ред. Ю.Н. Караулова. - М.: Азбуковник, 2008.

6. СЯД 2001 - Словарь языка Достоевского: лексический строй идиолекта / Под ред. Ю.Н. Караулова. - М.: Азбуковник, 2001. - Вып. І. - 442 с.

7. ТопоровВ.Н.Миф. Ритуал. Символ. Образ: Исследования в области мифопоэтического: Избранное. - М.: Прогресс-Культура, 1995. - 624 с.

8. Чернова Н.В. «Господин Прохарчин»: Символика огня // Достоевский: Материалы и исследования. Т. 13. - СПб.: Наука, 1996. С. 29-49.

\section{Шокиров Ш.И. \\ Вопросы перевода с одного языка на другой лексем с семантикой «кўз» (глаз) в английском и узбекском языках}

Андижанский государственный университет

(Узбекистан)

doi: $10.18411 / s p c-26-12-2017-05$

idsp: 000001:spc-26-12-2017-05

\section{Аннотация}

В статье освещаются структурные и семантические свойства конституентов лексико-семантического поля «Глаз(а)» английскогои узбекского языков.

Ключевые слова: лексико-семантическое поле, лексема,номинатив, коннотатив, ядро, периферия, план выражения,тематические группы. 